Esta revista forma parte del acervo de la Biblioteca Jurídica Virtual del Instituto de Investigaciones Jurídicas de la UNAM

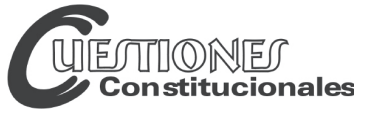

Revista Mexicana de Derecho Constitucional

Núm. 27, julio-diciembre 2012

\title{
AMPARO FEDERAL $V S$. AMPARO LOCAL LA INCERTIDUMBRE DE LA PROTECCIÓN CONSTITUCIONAL LOCAL FRENTE A LA JURISDICCIÓN FEDERAL
}

\author{
THE FEDERAL AMPARO SUIT VS. THE LOCAL AMPARO SUIT \\ THE VAGUENESS OF THE LOCAL CONSTITUTIONAL \\ SUPPORT FACING THE FEDERAL JURISDICTION
}

\begin{abstract}
RESUMEN: El artículo describe y analiza la inadecuada relación entre los órganos judiciales constitucionales federales y los locales en la tutela de los derechos fundamentales de carácter local. Se estudia la efectividad de las sentencias de amparo local y de las sentencias de amparo federal en los estados de Tlaxcala y Veracruz. El autor detalla la justicia constitucional local y las vicisitudes por las que atraviesa, actualmente, este medio de control y su reconocimiento en el ámbito federal.
\end{abstract}

Palabras clave: amparo federal, amparo local, federalismo judicial, protección constitucional, derechos fundamentales.

\section{Julio BustiLlos*}

ABSTRACT: the article describes and analyses the inappropriate relationship in the local level fundamental rights' tutelage between the federal and local judicial constitutional entities. It also analyses the judgments' effectiveness of the local and federal protection in Tlaxcala and Veracruz. The author details the local constitutional justice and the actual vicissitudes in which this means of control is found and its federal treatment.

Descriptors: federal amparo suit, local amparo suit, judicial federalism, constitutional protection, fundamental rights.

* Investigador en el Instituto de Investigaciones Jurídicas de la Universidad Nacional Autónoma de México.† 


\section{INTRODUCCIÓN}

La nueva jurisdicción contenciosa constitucional local del siglo veintiuno surge a través de las diversas reformas que realizaron a sus Constituciones 20 de las 32 entidades federativas.1 Ésta se configuró prácticamente a través del establecimiento de diversos medios de control de la constitucionalidad local, entre los que destaca el llamado "amparo local", instrumento protector de los derechos fundamentales, 2 establecido en las constituciones locales, concretamente en las de los estados de Tlaxcala y Veracruz. Y es precisamente la protección de los derechos fundamentales de índole estatal lo que lo hace distinto al amparo local del juicio de amparo de carácter federal, pues el amparo federal se circunscribe, entre otras cosas, a la tutela de las garantías individuales consagradas en la Constitución federal.

Ahora bien, el aparente fortalecimiento al federalismo que trajo la nueva jurisdicción constitucional estatal, trajo también una serie de cuestiones de diversa índole. Por ejemplo, se ha manifestado, entre otras cosas, que no existe la adecuada coordinación (normativa e institucional) entre los sistemas que conforman estos dos medios de control protectores de los derechos fundamentales; que las sentencias en amparo local no alcanzan el carácter definitivo o de cosa juzgada debido a la procedencia, en algunos casos, del amparo federal; que la preparación de los jueces estatales es deficiente para conocer y resolver asuntos de índole constitucional local y, por ende, que sus sentencias son de poca calidad.

El propósito general de este trabajo es ofrecer, por primera vez, una descripción y un análisis generales de la "efectividad" ("eficacia"/"eficiencia") de las sentencias en "amparo local" y la "efectividad" de las sentencias en amparo federal contra aquéllas sentencias locales. Para efectos de esta investigación la "eficacia" de las sentencias se observará cuando a través de éstas se restituyeron al ciudadano los derechos fundamentales que le fueron violados (esto es, cuando las sentencias se concedieron en favor del

1 Sobre el desarrollo de la nueva justicia constitucional local a través del análisis de sus sentencias, véase la segunda parte de nuestra obra La justicia constitucional en México. Análisis cuantitativo de las resoluciones judiciales en materia constitucional, México, UNAM, Instituto de Investigaciones Jurídicas, 2009.

2 En este trabajo, por conveniencia práctica, nos permitiremos utilizar la denominación "derechos fundamentales", agrupando con éste los derechos que tutelan tanto el juicio de protección constitucional, establecido en Tlaxcala, como el juicio de protección de derechos humanos, en Veracruz. 
ciudadano) o, en su defecto, la "ineficacia" de las sentencias (cuando éstas se negaron, sobreseyeron o desecharon), al no ser éstas el medio para que el ciudadano fuera restituido de sus derechos constitucionales.

Asimismo, la "eficacia" de las sentencias en amparo local se verá también cuando éstas no fueron impugnadas en amparo federal, lo cual significa que las sentencias locales lograron ser definitivas en su propio ámbito estatal con o sin la intervención de la jurisdicción federal de amparo (esto es, cuando las sentencias locales se impugnaron en amparo federal y en éste se confirmó el sentido del amparo local, es decir, no lo modificó en lo absoluto). Esto también pudiera traducirse en la existencia de una jurisdicción constitucional local de amparo más sólida, es decir, una autonomía e independencia judicial más fuerte frente a la jurisdicción federal de amparo.

Respecto a la "eficiencia", se observará a través de la duración de los juicios tanto de amparo local como de amparo federal. La finalidad es comparar la "efectividad" de ambos amparos y, con ello, determinar en lo posible, mediante elementos cuantitativos y cualitativos, qué instrumento de control constitucional protege mayormente los derechos fundamentales de los ciudadanos, y en este sentido, cabría cuestionarnos lo siguiente: ¿se justifica la procedencia del amparo federal contra el amparo local cuando se presentan violaciones directas o "indirectas" a la Constitución federal?; o, en el sentido de "sistema" o "complemento", ¿es viable la intervención de la jurisdicción federal de amparo cuando el amparo local no logra proteger los derechos fundamentales locales de sus ciudadanos o, en su defecto, no debería de intervenir en razón del reconocimiento y respeto de la autonomía judicial local?

Aparte de la información anterior que se pretende mostrar, se ofrecerán datos precisos sobre las características de las partes procesales, los derechos violados, los órganos jurisdiccionales involucrados, etcétera.

Lo anterior lo intentaremos responder, entre otros elementos, mediante el análisis detallado de expedientes de las sentencias en amparo local y en el caso de los datos sobre los amparos federales, nos basaremos sólo en información estadística general, debido a que desafortunadamente no pudimos obtener el texto de los expedientes respectivos. La cuestión de la falta de coordinación (normativa e institucional) entre la jurisdicción federal de amparo y la jurisdicción local de amparo, la trataremos al final de este trabajo, de manera valorativa y a modo de diagnóstico y propuesta. 
En estos dos párrafos siguientes, como marco teórico, nos referiremos muy brevemente al objeto esencial de análisis que configura la hipótesis general de este trabajo, es decir, al federalismo judicial ${ }^{3}$ o, si se nos permite la expresión, al "federalismo judicial constitucional". Asimismo, debido a que el federalismo judicial constitucional se realiza mediante la relación entre la justicia (constitucional) federal y la justicia (constitucional) local mediante la revisión federal (vía juicio de amparo) de las resoluciones locales, habremos de vincular el concepto de federalismo judicial constitucional con el concepto procesal conocido como "apelación" (técnicamente entendido como la revisión de resoluciones por parte de un órgano superior). ${ }^{4}$ Este vínculo lo realizaremos mediante la exposición sucinta de un criterio operativo en torno a la apelación, el cual sostiene que la función u objetivo de esta figura procesal es la de "corrección de errores"s de las correspondientes resoluciones.

Entonces, por "federalismo judicial constitucional" entenderemos, de manera muy sencilla, la adecuada relación entre los órganos judiciales constitucionales federales y los órganos judiciales constitucionales locales en un sistema federal. No obstante esta definición, cabe destacar que en todo sistema federal con una Constitución suprema (e incluso también en sistemas regionales con tribunales locales) existe la posibilidad de impug-

3 Sobre la definición del federalismo judicial, véase: Comba, Mario, Esperienze federaliste tra garantismo e democrazia. Il "judicial federalism" negli Stati Uniti, Napoli, Casa Editrice Jovene, 1996, 263; Fix-Zamudio, Héctor, "El Poder Judicial y el federalismo...”, op. cit., p. 138; Gudiño Pelayo José de Jesús, "Federalismo e independencia judicial”, Jus Semper Loquitur, núm. 30, octubre-diciembre, 2000, p. 15; Hernández Martínez, María del Pilar, "Del federalismo judicial”, Reforma Judicial. Revista Mexicana de Justicia, núm. 2, julio-diciembre de 2003, p. 229. También cfr. Bator, Paul et al., Hart and Wechsler's the Federal Courts and the Federal System, 3a. ed., Nueva York, The Foundation Press, Inc., 1988; y Ruiz, Gregorio, Federalismo judicial (el modelo americano), Madrid, Civitas, 1994. Por otro lado, sobre una breve exposición del federalismo judicial mexicano en materias civil, penal, administrativa y laboral, véase nuestro trabajo Federalismo judicial. Breve estudio sobre la relación entre la justicia local y la justicia federal a través de las resoluciones locales impugnadas en amparo federal, México, UNAM, Instituto de Investigaciones Jurídicas, 2010.

4 Shapiro, Martin, "Appeal", Law and Society Review, vol. 14, núm. 3, primavera de 1980, pp. 629-661.

5 Véase el modelo económico de Steven Shavell, en "The Appeals Process as a Means of Error Correction", Journal of Legal Studies,vol. 24, núm. 2, June, 1995, pp. 379-426. En el mismo sentido, véase: Barclay, Scott, "Posner's Economic Model and the Decision to Appeal”, Justice System Journal, vol. 19, núm. 1, pp. 77-99. 
nar, en ciertos casos, las resoluciones locales ante los tribunales federales o nacionales.

Para comenzar nuestro análisis a continuación se ofrece una tabla estadística con la información de los amparos locales interpuestos ante la jurisdicción contenciosa constitucional local, concretamente ante los órganos constitucionales de los Tribunales Superiores de Justicia de Tlaxcala ${ }^{6}$ y Veracruz, y que eventualmente fueron desechados o, en el supuesto de ser admitidos, sobreseídos o, en el caso de los asuntos que sí llegaron al estudio de fondo, concedidos o negados. La tabla también expone los juicios de amparo directo, ${ }^{7}$ así como un indirecto, promovidos y resueltos ante el Juzgado Segundo de Distrito en el Estado, el Primer Tribunal Colegiado en Materia Penal del Séptimo Circuito, el Primer Tribunal Colegiado en Materia Administrativa del Séptimo Circuito, el Segundo Tribunal Colegiado en Materia Administrativa del Séptimo Circuito y el Segundo Tribunal Colegiado en Materia Civil del Séptimo Circuito, contra las sentencias en amparo local dictadas solamente por la Sala Constitucional veracruzana, debido a que son las únicas sentencias de las que tuvimos conocimiento y obtuvimos la información respectiva.

6 En el caso de Tlaxcala solamente expondremos el análisis de 5 sentencias en amparo local ( 1 emitida en el 2005 y las restantes 4 en el 2006), que son las únicas de las que pudimos obtener alguna información. Desconocemos si éstas fueron impugnadas o no en amparo federal. Sin embargo, tenemos una referencia estadística general de que en el periodo 2002-2009 se han radicado 91 demandas de amparo local (2002: 2; 2003: 2; 2004: 1; 2005: 3; 2006: 12; 2007: 7; 2008: 8, y 2009: 58) ante el órgano constitucional del Tribunal Superior de Justicia de Tlaxcala. De estos 91 posibles juicios de amparo local, como ya señalamos, únicamente 5 sentencias se han hecho públicas. Desconocemos porqué el estado de Tlaxcala en particular no hace públicas las sentencias que refieren la protección de los derechos humanos en la entidad.

7 Sobre el amparo directo, al igual que aquí, desde una perspectiva cuantitativa y cualitativa, tanto histórica como actual, véase nuestra obra El amparo directo en México. Evolución y realidad actual, México, Porrúa-UNAM, Instituto de Investigaciones Jurídicas, 2008. 


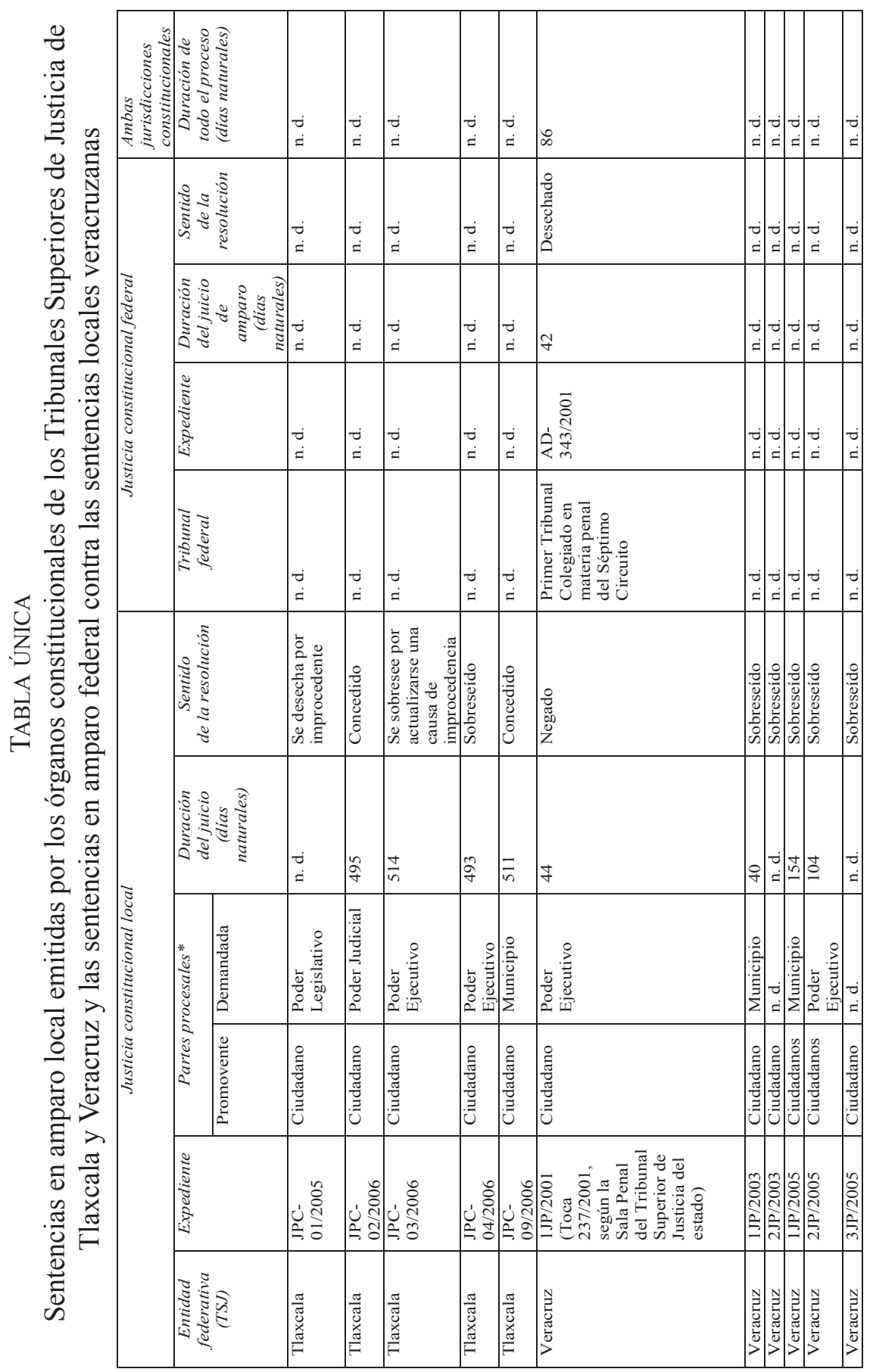




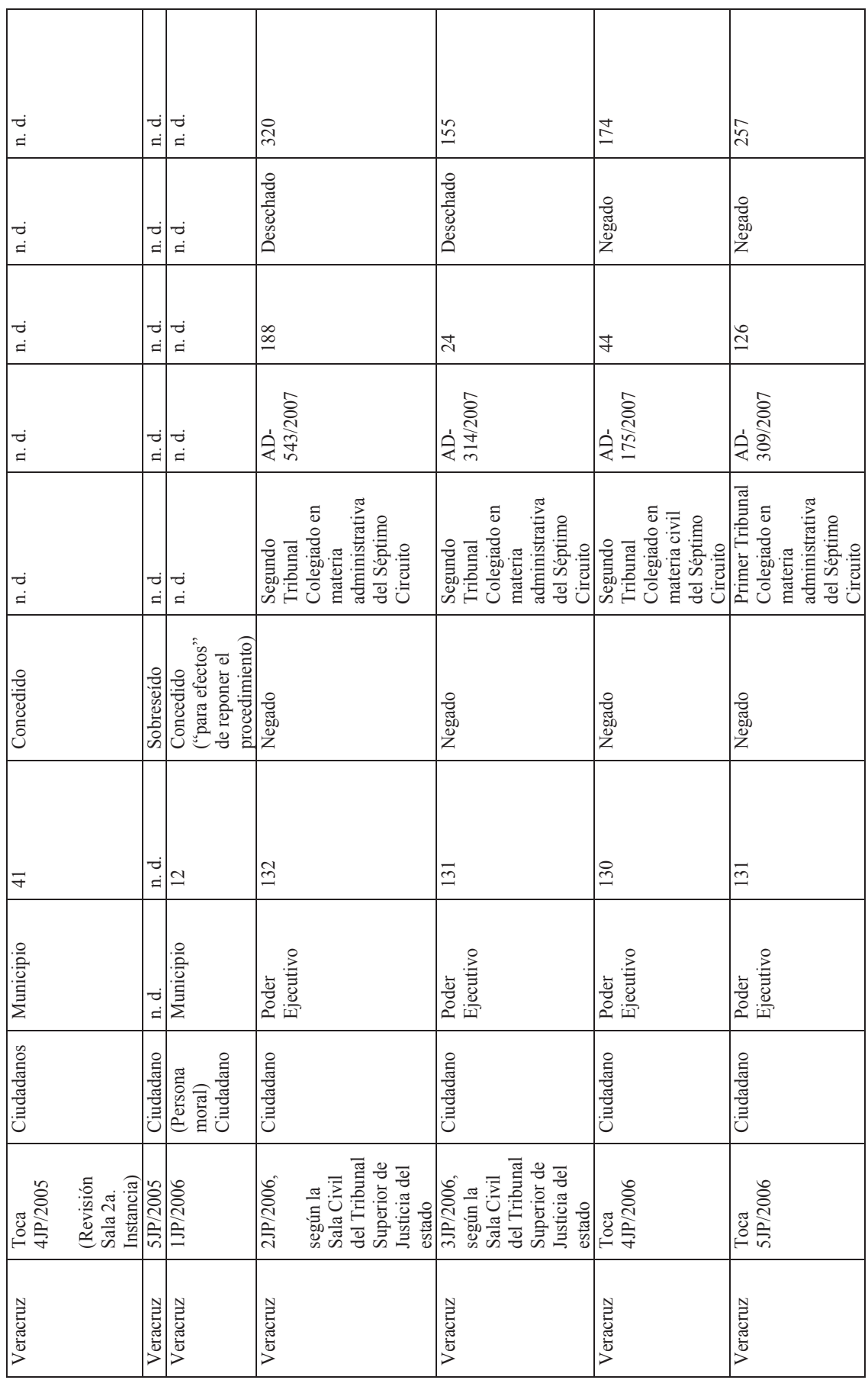




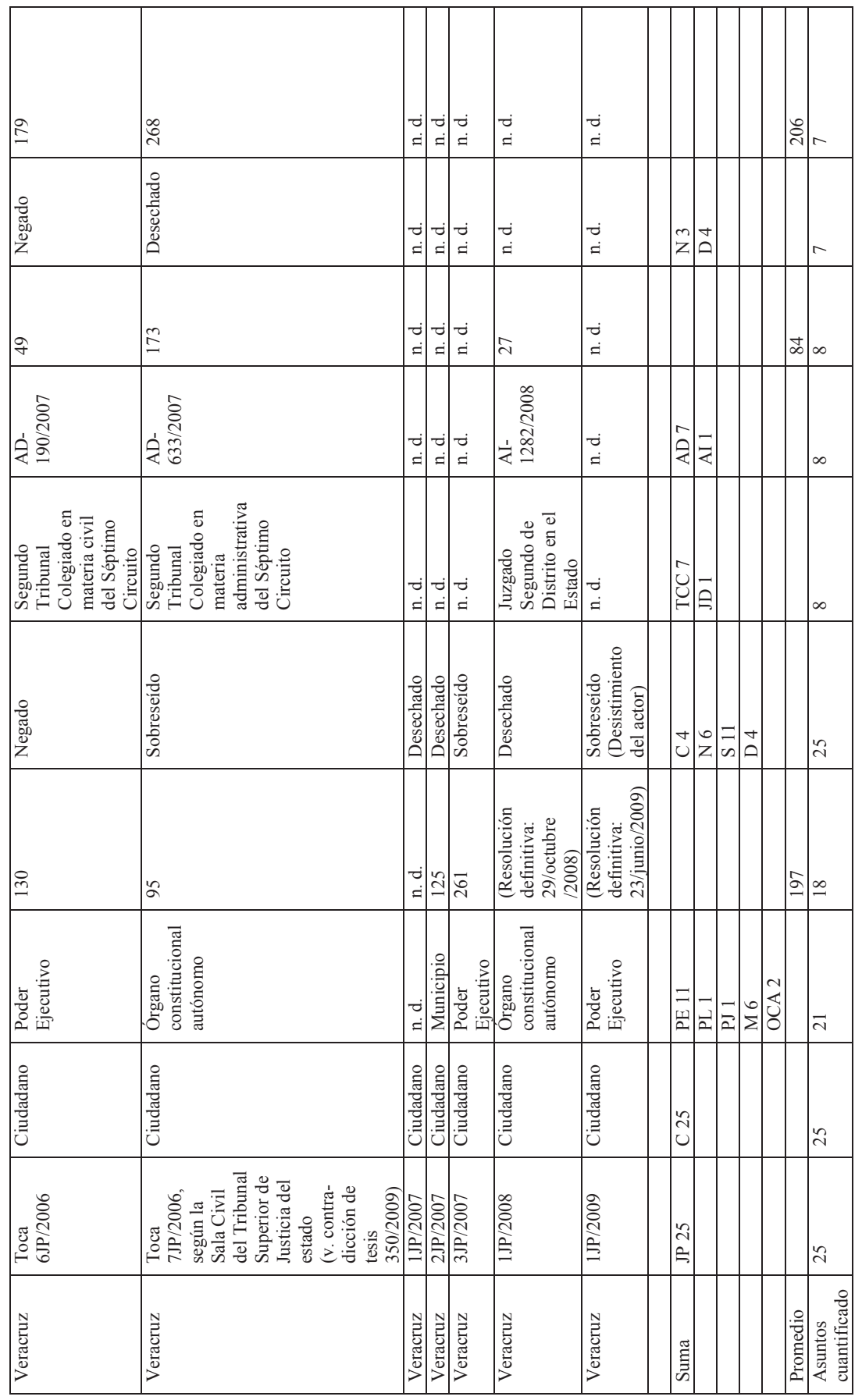




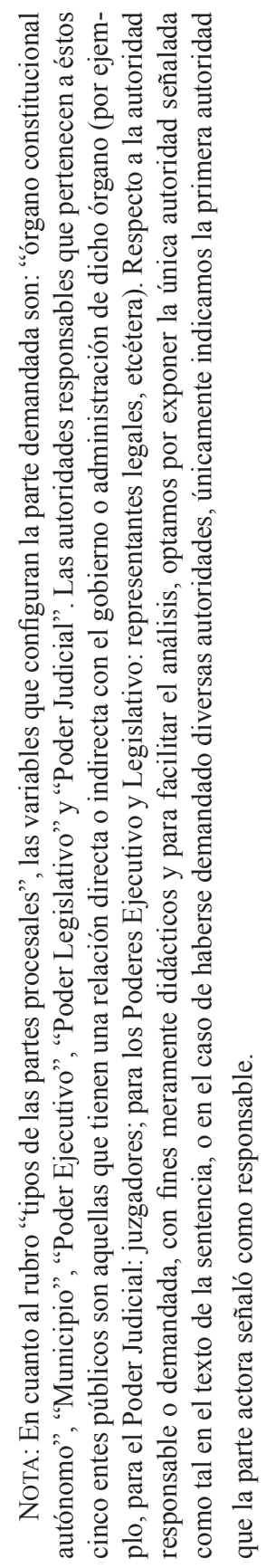

DR (C) 2012, Universidad Nacional Autónoma de México, Instituto de Investigaciones Jurídicas 


\section{ANÁLISIS DE LAS SENTENCIAS EN AMPARO LOCAL}

\section{Sentencias}

\section{A. Tlaxcala}

El primer amparo local, registrado con el número de expediente JPC1/2005, fue interpuesto ante el Tribunal Superior de Justicia de Tlaxcala, erigido en Tribunal Constitucional, por el ciudadano tlaxcalteca Rafael Juárez Castañeda. El quejoso adujo como actos reclamados algunos actos emitidos por el Congreso del Estado de Tlaxcala. El 12 de enero de 2005 el Tribunal Constitucional estimó que la demanda de amparo no cubría requisitos formales para su admisión, y por ende la desechó.

El segundo amparo local, registrado con el número de expediente JPC02/2006, fue interpuesto el 2 de enero de 2006 ante el Tribunal Constitucional de Tlaxcala por el ciudadano Rafael Molina Jiménez, diputado de la LVIII Legislatura del Congreso del Estado de Tlaxcala. El afectado señaló como autoridad responsable a la magistrada presidenta del Tribunal Superior de Justicia del Estado. El acto reclamado consistió en el Acuerdo emitido por dicho Tribunal, en el que se otorgó la suspensión del acto reclamado a las autoridades responsables que evitaron que el actor continuara en el proceso de selección para ser auditor de Fiscalización Superior del Congreso local. Si fueron motivos políticos o, incluso, personales no se especifican. Sin embargo, el quejoso promovió el amparo aduciendo que le violaron en su contra la garantía de legalidad, al no cumplirse con lo legalmente establecido para la realización de dicho proceso.

El 17 de mayo de 2007 el Tribunal Constitucional tlaxcalteca al entrar al estudio de fondo del asunto estimó que efectivamente se le habían violado derechos constitucionales locales, y por ende concedió al quejoso la protección constitucional del amparo.

El tercer amparo local, registrado con el número de expediente JPC-3/2006, fue interpuesto el 9 de enero de 2006 ante el Tribunal Constitucional local por la ciudadana Lilia Ortega Paredes, en su carácter de apoderada legal de la empresa purificadora de agua "El aljibe". La quejosa señaló como autoridades responsables al gobernador, a los integrantes del Congreso, al presidente municipal de Apizaco y al Consejo Directivo de Agua Potable y Alcantarillado municipal. El acto reclamado aducido fue el Acuerdo por el que se autorizaron las tarifas de agua potable. El 13 de junio de 2007 el 
órgano constitucional local determinó sobreseer el juicio en razón de que al examinar los requisitos de forma se actualizó una causal de improcedencia, lo cual impidió entrar al estudio de fondo.

El cuarto amparo local, registrado con el número de expediente JPC4/2006, fue interpuesto el 10 de enero de 2006 ante el órgano constitucional tlaxcalteca por la ciudadana Dora Elena Reséndiz Pérez, propietaria de la empresa "Agua purificada Oliazul". Las autoridades señaladas como responsables fueron el gobernador, los miembros del Congreso, el presidente municipal de Apizaco y el Consejo Directivo de Agua Potable y Alcantarillado Municipal. La actora impugnó como acto reclamado el Acuerdo por el que se autorizaron las tarifas de agua potable. El 17 de mayo de 2007 el tribunal de control constitucional local estimó que había un impedimento procesal para entrar al fondo y resolverlo, por lo que decidió declarar el sobreseimiento del asunto.

En los amparos JPC-3/2006 y JPC-4/2006 los quejosos, propietarios de empresas de purificación y venta del agua purificada, reclamaron que el acto por el cual se autorizaron las tarifas de agua potable les afectaron sus derechos de igualdad (proporcionalidad fiscal) y de trabajo, debido a que las nuevas tarifas establecieron cuotas especiales para las empresas que comercializan con el vital líquido.

El quinto amparo local, registrado con el número de expediente JPC9/2006, fue interpuesto el 29 de junio de 2006 ante el Tribunal Constitucional local por el ciudadano tlaxcalteca Armando Casas Barrera, en su calidad de director de Obras Públicas del municipio de Apizaco, Tlaxcala. Señaló como autoridades responsables las pertenecientes al propio Ayuntamiento del municipio de Apizaco, Tlaxcala, concretamente su presidente, secretario y síndico. Como acto reclamado el quejoso adujo la separación de su cargo de director de Obras Públicas, así como la negativa para retribuirle su remuneración correspondiente. El 30 de noviembre de 2007, el órgano de control constitucional tlaxcalteca estimó que efectivamente se habían violado derechos en contra del quejoso, por lo que le concedió el amparo y protección de la justicia local.

\section{B. Veracruz}

El primer amparo local, registrado con el expediente número 1JP/2001, fue interpuesto el 2 de marzo de 2001 por el ciudadano Tomás Chaparro 
Plata Ortiz ante la Sala Constitucional del Tribunal Superior de Justicia de Veracruz contra el fallo emitido el 27 de febrero de 2001 por la Sala Penal del propio Tribunal estatal en el juicio número 237/2001, instruido en contra del quejoso, por su probable participación en la comisión de diversos delitos del orden patrimonial. La demanda penal fue promovida por autoridades del gobierno del estado en contra de dicho acusado.

La Sala Constitucional estimó que sí era competente para conocer del amparo local, y al entrar al fondo del asunto consideró que el órgano jurisdiccional del fuero común había fundado y motivado el fallo penal; por lo que en su sesión del 16 de abril de 2001 resolvió negar el amparo al quejoso por no asistirle la razón.

El segundo amparo local, registrado con el expediente número 1JP/2003, fue interpuesto el 7 de enero de 2004 por el ciudadano Juan Ventura Zepeda ante la Sala Constitucional veracruzana en contra de los actos de autoridad efectuados por José Crispín Hernández Romero y Adolfo Guevara González en su carácter de presidente y síndico de un municipio.

El órgano jurisdiccional constitucional local estimó que era competente para conocer y resolver el asunto. Sin embargo, al analizar el asunto en cuanto a la forma, consideró que se actualizaba una causal de improcedencia, lo cual impidió que se llegara al fondo de la litis, razón por la que el 17 de febrero de 2004 dicho órgano decidió sobreseerlo.

El tercer amparo local, registrado con el expediente número 2JP/2003, fue interpuesto por un ciudadano veracruzano ante la Sala Constitucional veracruzana en contra de los actos de autoridades correspondiente al municipio.

El órgano jurisdiccional constitucional local estimó que era competente para conocer y resolver el asunto. Sin embargo, al analizar el asunto en cuanto a la forma, consideró que se actualizaba una causal de improcedencia, lo cual impidió que se llegara al fondo de la litis, razón por la que dicho órgano decidió sobreseerlo.

El cuarto amparo local, registrado con el expediente número 1JP/2005, fue interpuesto el 7 de abril de 2006 por los ciudadanos Jesús Juan Fernández Domínguez y otros ante la Sala Constitucional veracruzana en contra de los actos de autoridades correspondiente al municipio.

El órgano jurisdiccional constitucional local estimó que era competente para conocer y resolver el asunto. Sin embargo, al analizar el asunto en cuanto a la forma, consideró que se actualizaba una causal de improceden- 
cia, lo cual impidió que se llegara al fondo de la litis, razón por la que el 11 de septiembre de 2006 dicho órgano decidió sobreseerlo.

El quinto amparo local, registrado con el expediente número 2JP/2005, fue interpuesto el 16 de marzo de 2005 por el ciudadano Rafael Agustín Hernández Virúes ante la Sala Constitucional del Tribunal Superior de Justicia de Veracruz contra el acto de ejecución de la sentencia de 21 de febrero de 2005, en el expediente administrativo de responsabilidad 202/2003. El quejoso señaló como autoridades responsables del acto reclamado al procurador y subprocuradora de la Procuraduría General de Justicia del Estado.

El órgano jurisdiccional constitucional local estimó que era competente para conocer y resolver el asunto. Sin embargo, al analizar el asunto en cuanto a la forma, consideró que se actualizaba una causal de improcedencia, lo cual impidió que se llegara al fondo de la litis, razón por la que el 30 de junio de 2005 dicho órgano decidió sobreseerlo.

El sexto amparo local, registrado con el expediente número 3JP/2005, fue interpuesto por un ciudadano veracruzano ante la Sala Constitucional veracruzana en contra de los actos de autoridades correspondiente al municipio.

El órgano jurisdiccional constitucional local estimó que era competente para conocer y resolver el asunto. Sin embargo, al analizar el asunto en cuanto a la forma, consideró que se actualizaba una causal de improcedencia, lo cual impidió que se llegara al fondo de la litis, razón por la que dicho órgano decidió sobreseerlo.

El séptimo amparo local, registrado con el expediente número 4JP/2005, fue interpuesto el 19 de septiembre de 2005 por los ciudadanos Epifanio Ramos García e Isabel Hernández Hernández ante la Sala Constitucional veracruzana contra la resolución del juez Segundo de Primera Instancia de Poza Rica, emitida en virtud de una demanda interpuesta por el presidente municipal y otros, y que culminó en la clausura definitiva de un local comercial propiedad de los quejosos, lo cual les produjo pérdidas económicas, de las cuales, por medio del amparo local, los quejosos reclaman su reparación.

El órgano constitucional local admitió la demanda de amparo, entró al estudio de fondo y el 31 de octubre de 2005 decidió otorgar el amparo pero "para efectos" de que el juez del fuero común repusiera parte del procedimiento en el sentido de que, previo a dictar una nueva sentencia, solicitara a la autoridad político-administrativa responsable algunos requerimientos. 
El octavo amparo local, registrado con el expediente número 5JP/2005, fue interpuesto por un ciudadano veracruzano ante la Sala Constitucional veracruzana en contra de los actos de autoridades correspondiente al municipio.

El órgano jurisdiccional constitucional local estimó que era competente para conocer y resolver el asunto. Sin embargo, al analizar el asunto en cuanto a la forma, consideró que se actualizaba una causal de improcedencia, lo cual impidió que se llegara al fondo de la litis, razón por la que dicho órgano decidió sobreseerlo.

El noveno amparo local, registrado con el expediente número 1JP/2006, fue interpuesto el 10 de octubre de 2007 por Héctor Gerardo Peña García (en su carácter de apoderado legal de Comercial Yuquín, S. A. de C. V.) ante la Sala Constitucional de Veracruz contra la resolución de un juez del fuero común, dictada como consecuencia de una demanda promovida por el presidente municipal y otras autoridades de ese Ayuntamiento veracruzano.

El tribunal constitucional local admitió la demanda de amparo, entró al estudio de fondo y el 22 de octubre de 2005 decidió conceder el amparo pero "para efectos" de que el juez de primera instancia repusiera el procedimiento.

El décimo amparo local, registrado con el expediente número 2JP/2006, fue interpuesto el 19 de septiembre de 2006 por el ciudadano Pascual Chontal Cayetano ante la Sala Constitucional de Veracruz contra la sentencia, negada al actor, dictada el 1o. de febrero de 2006 por la Sala Civil del Tribunal Superior de Justicia del mismo estado.

El décimo primer amparo local, registrado con el expediente número 3JP/2006, fue interpuesto el 19 de septiembre de 2006 por Jesús Antonio Marcial Cisneros ante la Sala Constitucional veracruzana contra la sentencia, negada al actor, dictada el 31 de enero de 2006 por la Sala Civil del Tribunal Superior de Justicia del mismo estado.

El décimo segundo amparo local, registrado con el expediente número 4JP/2006, fue interpuesto el 21 de septiembre de 2006 por Adolfo Jesús Paredes Paredes ante la Sala Constitucional de Veracruz contra la sentencia, negada al actor, dictada el 31 de enero de 2006 por la Sala Civil del Tribunal Superior de Justicia del mismo estado.

El décimo tercer amparo local, registrado con el expediente número $5 \mathrm{JP} / 2006$, fue interpuesto el 21 de septiembre de 2006 por Octavio Ignacio Escobar Bernal ante la Sala Constitucional veracruzana contra la sentencia, negada al actor, dictada el 2 de febrero de 2006 por la Sala Civil del Tribunal Superior de Justicia del mismo estado. 
El décimo cuarto amparo local, registrado con el expediente número 6JP/2006, fue interpuesto el 21 de septiembre de 2006 por Elías Escobar Bernal ante la Sala Constitucional de Veracruz contra la sentencia, negada al actor, dictada el 31 de enero de 2006 por la Sala Civil del Tribunal Superior de Justicia del mismo estado.

Los cinco amparos locales recién referidos (2JP/2006, 3JP/2006, 4JP/2006, $5 \mathrm{JP} / 2006$ y $6 \mathrm{JP} / 2006$ ) se originaron a raíz de la petición que los quejosos le plantearon al gobernador veracruzano, solicitándole una concesión de trasporte público de taxi, de la cual no obtuvieron respuesta en el término que establece la legislación respectiva. Ante este acto de omisión, los quejosos promovieron dichos amparos en razón de que estimaron violados en su contra los derechos de petición y de trabajo.

El tribunal ordinario expuso diversos argumentos para emitir su sentencia, entre los que destacan que la omisión de la autoridad para contestar no actualizaba la vulneración del derecho de petición, ya que no se trataba de una petición efectuada de un gobernado a una autoridad, sino que configuraba una solicitud de concesión. En este tenor, se trataba de un procedimiento administrativo en el que al no concretarse el mismo (en el sentido de obtener una respuesta) se actualizaba una negativa ficta, la cual se combatía por medio de un juicio contencioso administrativo. Además, el peticionario se dirigió erróneamente ante el gobernador que era una autoridad no competente para emitir dicha concesión, ya que la competente era la Dirección General de Tránsito y Transporte del Estado.

Por otro lado, si los quejosos hubieran pretendido acudir a la justicia constitucional local, primero debieron agotar la instancia común administrativa a través de los recursos disponibles para el caso. Por tanto, por estas razones la Sala Constitucional decidió negar a los quejosos la protección de la justicia constitucional local en razón de que los actos reclamados se trataban de infracciones administrativas y no de violaciones a derechos humanos establecidos en la Constitución veracruzana.

El décimo quinto amparo local, registrado con el expediente número 7JP/2006, fue interpuesto el 26 de octubre de 2006 por León Ignacio Ruiz Ponce ante la Sala Constitucional veracruzana contra la sentencia, negada al actor, dictada el 31 de enero de 2006 por la Sala Civil del Tribunal Superior de Justicia del mismo estado.

La demanda de amparo local se originó, por un lado, a raíz de la entrada en vigor del Código 590 Electoral para el Estado de Veracruz, el cual 
le coartaba al quejoso su derecho para formar una asociación ciudadana (“Agrupación Ciudadana Municipal”) que permitiera postular candidatos independientes para contender a la presidencia municipal, es decir, sin pertenencia a ningún partido político, y por otro lado, a la desatención de la Comisión Estatal de Derechos Humanos (facultada para promover amparos locales) para investigar si dicho ordenamiento violaba algún derecho humano establecido en la Constitución veracruzana, especialmente el derecho de votar y ser votado.

El órgano jurisdiccional constitucional local estimó que el quejoso no había probado su acción, en el sentido de que no probó que los derechos aducidos como conculcados en su contra fueran ciertos, además de que se actualizaron algunas causales que impidieron que dicho tribunal llegara al estudio del fondo del asunto; por lo que en su sesión del 31 de enero del 2007 decidió sobreseer el amparo.

Cabe señalar que a raíz de este juicio de amparo local 7JP/2006, mucho tiempo después, el 31 de agosto de 2009, la Sala Constitucional veracruzana dictó un auto, que para su cumplimiento la propia Sala denunció una contradicción de tesis ante la Suprema Corte, de la cual se hará referencia más adelante.

El décimo sexto amparo local, registrado con el expediente número $1 \mathrm{JP} / 2007$, fue interpuesto por un ciudadano veracruzano ante la Sala Constitucional veracruzana en contra de los actos de autoridades correspondiente al municipio.

El órgano jurisdiccional constitucional local estimó que era competente para conocer y resolver el asunto. Sin embargo, al analizar el asunto en cuanto a la forma, consideró que se actualizaba una causal de improcedencia, lo cual impidió que se llegara al fondo de la litis, razón por la que dicho órgano decidió sobreseerlo.

El décimo séptimo amparo local, registrado con el expediente 2JP/2007, fue interpuesto el 26 de enero de 2007 por la ciudadana Mónica del Carmen Domínguez Montalvo ante la Sala Constitucional de Veracruz contra la resolución del juez de primera instancia del municipio de Alvarado, derivada del juicio iniciado por la demanda que interpuso Santa Vera Herrera, en su carácter de agente municipal de la localidad de "El Bayo", municipio de Alvarado. La quejosa reclamó que se había violado en su contra el derecho de propiedad (sobre un terreno ejidal de su pertenencia). 
El tribunal constitucional local consideró que sí era legalmente competente para conocer y resolver el asunto. Sin embargo, al empezar a substanciar el juicio de amparo sobrevino una causal de improcedencia en cuanto a que la actora decidió desistirse del mismo. Por tanto, el 31 de mayo de 2007 el tribunal desechó la demanda.

El décimo octavo amparo local, registrado con el expediente número 3JP/2007, fue interpuesto el 6 de julio de 2007 por la ciudadana Graciela Patricia Huerta Giles ante la Sala Constitucional veracruzana contra la resolución del juez de primera instancia de Jalapa, derivada del juicio incoado por la demanda presentada por Natalio A. Arrieta Castillo y Concepción Bonola García, en su carácter de director General de Educación Primaria de la SEP estatal y supervisora escolar de la zona 074 de Jalapa. La actora reclamó que se había violado en su contra el derecho a la intimidad, en razón de que la autoridad responsable había inducido psicológicamente a aquélla para realizar una conducta ajena a la voluntad de la misma.

El tribunal constitucional local consideró que sí era legalmente competente para conocer y resolver el asunto. Sin embargo, al empezar a substanciar el juicio de amparo sobrevino una causal de improcedencia en cuanto a que la actora decidió desistirse del mismo. Por tanto, el 27 de marzo de 2007 el tribunal no entró al fondo del asunto y sobreseyó el juicio.

\section{Análisis}

De los 25 amparos locales que tuvimos información, que fueron radicados ante los órganos constitucionales locales durante el periodo 2001-2009, únicamente analizaremos de manera muy breve 18 (JPC-2/2006, JPC-3/2006, JPC-4/2006, JPC9/2006, 1JP/2001, 1JP/2003, 1JP/2005, 2JP/2005, 4JP/2005, 1JP/2006, 2JP/2006, 3JP/2006, 4JP/2006, 5JP/2006, 6JP/2006, 7JP/2006, 2JP/2007 y 3JP/2007), en razón de que de éstos últimos obtuvimos datos más completos, tales como las características de las partes procesales, los actos reclamados, la duración de los juicios y el sentido de las resoluciones. Además de éstas características, en el análisis propuesto nos enfocaremos principalmente a exponer los derechos fundamentales que los quejosos reclamaron como violados.

Los actos que más reclamaron los quejosos en los amparos locales fueron las sentencias emitidas por los jueces del fuero común, de las cuales generalmente se reclamó su falta de motivación y fundamentación, es decir, el deber de expresar los motivos de hecho y las razones de derecho. 
Las sentencias en las que se observó dicha falta al principio de legalidad se señalan a continuación, así como una breve referencia de su sentido de resolución: (JPC-2/2006: fallo en favor de los diputados tlaxcaltecas demandados; 1JP/2001: fallo en contra del quejoso por su probable participación en la comisión de delitos del orden patrimonial; 2JP/2005: acto de ejecución de la sentencia que inculpa al quejoso como culpable de responsabilidad administrativa; 4JP/2005: fallo que ordena la clausura de un comercio propiedad del quejoso; 2JP/2006, 3JP/2006, 4JP/2006, 5JP/2006 y 6JP/2006: fallos que niegan la razón a los quejosos en cuanto a que el gobernador de Veracruz no incurrió en falta administrativa alguna al no responderles a la solicitud de concesión de transporte público de taxi; 7JP/2006: fallo que niega la razón al quejoso en cuanto a que la Comisión Estatal de Derechos Humanos no incurrió en responsabilidad alguna al desatender la solicitud que le planteó para que promoviera un amparo local; 2JP/2007: fallo en contra del quejoso y que da la razón a un agente municipal que realizó un acto de autoridad en afectación de la propiedad del quejoso; 3JP/2007: fallo que favoreció a un funcionario de Educación de Veracruz, que indujo psicológicamente al quejoso a realizar un acto ajeno a su voluntad).

En cuanto a los derechos fundamentales reclamados como violados en los amparos locales, en cuatro ocasiones se señaló la garantía de legalidad. La violación consistió básicamente en que no se observaron las formalidades que la normativa respectiva establecía para la realización del acto o actos correspondientes: (4JP/2005: procedimiento administrativo de clausura de comercio; JPC-2/2006: proceso de selección para auditor de Fiscalización Superior del Congreso de Tlaxcala; JPC-9/2006: procedimiento administrativo de separación de cargo; 2JP/2007: procedimiento judicial o administrativo de despojo).

Sobre el primer caso de los mencionados en el párrafo anterior (4JP/2005), el quejoso, a la par de la garantía de legalidad señalada como violada, también reclamó que se le violó su derecho al trabajo, en virtud de que con el acto arbitrario de autoridad, consistente en la clausura definitiva de su fuente de trabajo, se violó su derecho al mismo.

En el caso JPC-2/2006 el quejoso, a la par de la garantía de legalidad señalada como violada, también reclamó que se le violó su derecho de igualdad al no permitírsele arbitrariamente que participara en igualdad de circunstancias en el proceso de selección para auditor de Fiscalización Superior del Congreso de Tlaxcala. 
En el caso JPC-9/2006 el quejoso, a la par de la garantía de legalidad señalada como violada, también reclamó que se le violó su derecho al trabajo al no permitírsele arbitrariamente que continuara desempeñándose como director de Obras Públicas del municipio de Apizaco, Tlaxcala; asimismo, consideró que le violaban en su persona el derecho de igualdad, al no proporcionarle su remuneración, al igual que al resto de sus compañeros.

En el 2JP/2007, a la par de la garantía de legalidad, el derecho de propiedad señaló el quejoso como violado en su contra; por tal razón el quejoso buscó ampararse contra la sentencia local que dio la razón a un agente del municipio de Alvarado, Veracruz, quien mediante un acto de autoridad despojó arbitrariamente al quejoso de su propiedad.

El derecho de igualdad (en cuanto al principio de proporcionalidad fiscal) se reclamó como violado también en otras dos ocasiones. Aquí los quejosos estimaron que, como personas morales que configuraban sus empresas, se les aplicaba desigualmente las nuevas tarifas de agua potable. Dicha violación, argumentaron los quejosos, se extendía incluso a la violación del derecho al trabajo en razón de que al aplicárseles cobros fiscales de manera desigual, afectaba la fuente de trabajo, limitándoles su derecho al mismo.

Los derechos de petición y de trabajo se reclamaron como violados en cinco ocasiones (2JP/2006, 3JP/2006, 4JP/2006, 5JP/2006 y 6JP/2006). Aquí los quejosos al no obtener respuesta a su solicitud administrativa de concesión de taxi hecha al gobernador de Veracruz, pese a que se trataba sólo de un trámite administrativo ante una autoridad ajena al mismo, estimaron que se violaron en su contra el derecho de petición y, al no haber obtenido la concesión para desarrollar su fuente de trabajo, también su derecho al trabajo.

En el amparo local 7JP/2006 el quejoso adujo que se le violaron en su contra el derecho a la libre asociación y el derecho a votar y ser votado, debido a que pretendía formar una asociación "ciudadana" que postulara candidatos independientes a cargos de elección popular; situación que se obstaculizó al entrar en vigor el Código 590 Electoral para el Estado de Veracruz, el cual prohibía postular candidatos independientes.

En el 3JP/2007 la violación del derecho a la intimidad fue reclamada por un quejoso que buscó el amparo de la justicia local contra la sentencia emitida en favor de un funcionario de Educación de Veracruz, que lo indujo psicológicamente a realizar una conducta ajena a la voluntad de dicho quejoso. 
Como se aprecia de los 18 amparos locales estudiados con antelación, en sólo 13 se determinaron con precisión los derechos y garantías fundamentales violados, los cuales se resumen a continuación: (JPC-2/2006) garantía de legalidad y derecho al trabajo; (JPC-3/2006 y JPC-4/2006) derechos de igualdad y al trabajo; (JPC9/2006) garantía de legalidad y derechos al trabajo y de igualdad; (4JP/2005) garantía de legalidad y derecho al trabajo; (2JP/2006, 3JP/2006, 4JP/2006, 5JP/2006 y 6JP/2006) derechos de petición y al trabajo; (7JP/2006) derechos de libre asociación y de votar y ser votado; (2JP/2007) de legalidad y de propiedad, y (3JP/2007) derecho a la intimidad.

Lo anterior nos muestra que el derecho al trabajo (10 ocasiones) fue el más señalado como violado, mientras que los medianamente reclamados fueron los derechos de petición (5 ocasiones) y la garantía de legalidad (4 ocasiones); quedando en menor proporción los derechos de igualdad (2 ocasiones), de propiedad (1 ocasión) y a la intimidad (1 ocasión).

De lo brevemente expuesto en los 18 amparos locales, se observa también que los ciudadanos que reclamaron la violación de sus derechos fundamentales lo hicieron señalando como autoridades responsables, en una ocasión, a un integrante del Poder Judicial local (magistrada); en dos ocasiones, a una dependencia de un Ayuntamiento (Consejo Directivo de Agua Potable y Alcantarillado Municipal); en seis ocasiones, a alguna o algunas autoridades de un Ayuntamiento (presidente municipal, secretario, síndico y agente); en una ocasión, a dos integrantes de la Procuraduría General de Justicia local (procurador y subprocuradora); en seis ocasiones, al gobernador de un estado o autoridades de su gobierno; en una ocasión, al Congreso local, y en una ocasión, a un funcionario del Poder Ejecutivo local (director general de la Secretaría de Educación Pública del Estado).

Lo anterior nos indica que las autoridades mayor y menormente demandadas pertenecen a los siguientes órganos locales de gobierno: al Poder Ejecutivo (ocho ocasiones); al municipio (también en ocho ocasiones); al Poder Judicial (en una ocasión), y Poder Legislativo (en una ocasión).

Respecto al sentido de las resoluciones en amparo local se observa que de los 18 amparos analizados, cuatro se concedieron (tres de modo liso y llano y uno "para efectos"), seis se negaron, siete se sobreseyeron y sólo uno se desechó. Esto significa que en la mayoría de los juicios de amparo local (10) se entró al fondo del asunto y en el resto (ocho), no se llegó a tal estudio. 
Tocante a la duración de los juicios de amparo local, se tiene que el promedio de los 18 analizados fue de 197 días naturales, es decir, seis meses y medio meses. Esta demora de los juicios es muy relativa y puede generarse por diversos motivos, tales como la repetitividad del acto reclamado (por ejemplo, en cinco ocasiones se reclamó el mismo acto de la misma autoridad, lo cual condujo al juzgador a resolver el primer amparo en cuatro meses y 10 días, y los cuatro restantes, el mismo día y uno y dos días después), los derechos fundamentales violados (principalmente cuando se reclamó la violación de más de un derecho fundamental de carácter local o cuando se señaló una violación "indirecta" $\mathrm{o}$, incluso, directa a la Constitución federal), las autoridades involucradas, etcétera.

Cabe señalar que, como lo advertimos al inicio, los amparos locales analizados pertenecen a dos entidades federativas: Tlaxcala y Veracruz. En cuanto a la duración de los juicios de amparo, se observa una marcada diferencia entre los emitidos en Tlaxcala y en Veracruz. El promedio de duración de los 4 amparos locales tlaxcaltecas (495, 514, 493 y 511) fue de 503 días naturales, es decir, 17 meses; ${ }^{8}$ mientras que el promedio de los 14 juicios veracruzanos apenas alcanzó 109 días naturales, es decir, tres meses y medio.

8 Curiosamente la Ley de Control Constitucional del Estado de Tlaxcala que entró en vigor el 15 de enero de 2002, establece en su artículo 34, párrafo 2o., que "Las sentencias deberán dictarse en un término no mayor de 90 días naturales, contados a partir del día siguiente de la presentación de la demanda. La contravención a lo anterior se sancionará conforme a las leyes respectivas a la materia". Énfasis nuestro. Esto nos hace pensar que en el estado de Tlaxcala los tiempos procesales para resolver los juicios de amparo no se respetan, ni se respetan los lineamientos de transparencia que obligan a publicar las resoluciones emitidas por el Tribunal de Control Constitucional de Tlaxcala, que de acuerdo con información que tenemos, y que ya la expusimos arriba, durante el periodo 2002-2009 se han radicado 91 demandas de amparo local ante dicho Tribunal, sin que hasta ahora conozcamos lo que sucedió después, excepto de las 5 sentencias que aquí expusimos. 
III. ANÁLISIS DE LAS SENTENCIAS EN AMPARO LOCAL IMPUGNADAS EN AMPARO FEDERAL

1. Sentencias (y criterios interpretativos y contradicción de tesis)

\section{A. Veracruz}

El primer amparo federal, de tipo directo (al igual que el resto, excepto el último que es amparo indirecto), registrado con el expediente número AD343/2001, fue interpuesto el 29 de agosto de 2001 por el ciudadano Tomás Chaparro Plata Ortiz ante el Primer Tribunal Colegiado en Materia Penal del Séptimo Circuito contra la resolución dictada el 16 de abril de 2001 por la Sala Constitucional del Tribunal Superior de Justicia de Veracruz, con motivo del recurso de queja interpuesto por el quejoso en contra del acuerdo de no ejercicio de la acción penal emitido en el juicio de amparo local 1/2001. De lo cual, el quejoso adujo como conculcadas en su contra las garantías previstas en los artículos 14, 16, 17 y 20 de la Constitución federal.

El tribunal de amparo en su sesión del 11 de octubre de 2001 se declaró legalmente incompetente para conocer del asunto. En tal virtud, decidió desechar la demanda de amparo por considerarlo improcedente. Los razonamientos esgrimidos por el colegiado para estimar improcedente el amparo directo se refirieron básicamente a que el acuerdo impugnado, aunque haya sido emitido por un tribunal judicial, no configuraba una sentencia definitiva que pusiera fin al juicio ni tampoco lo dio por concluido, ya que la resolución reclamada se pronunció con motivo de la interposición de un medio de impugnación en contra del acuerdo dictado en las diligencias de averiguación previa seguidas por el Ministerio Público, de donde se siguió que ese acuerdo fue dictado fuera del juicio; luego entonces, se trataba de un acto reclamable en amparo indirecto, de conformidad con lo dispuesto por el artículo 114, fracción III, de la Ley de Amparo. 
Cabe señalar que la resolución anterior dio pauta para que en abril de 2002 el propio Primer Tribunal Colegiado en Materia Penal del Séptimo Circuito emitiera una tesis aislada. ${ }^{9}$

El segundo amparo directo, registrado con el expediente número AD175/2007, fue interpuesto el 28 de febrero de 2007 por el ciudadano Adolfo Jesús Paredes Paredes ante el Segundo Tribunal Colegiado en Materia Civil del Séptimo Circuito contra el fallo en amparo local 4/2006, negado en su contra, emitido el 31 de enero de 2007 por la Sala Constitucional del Tribunal Superior de Justicia de Veracruz.

El tercer amparo directo, registrado con el expediente número AD190/2007, fue interpuesto el 28 de febrero de 2007 por el ciudadano Elías Escobar Bernal ante el Tercer Tribunal Colegiado en Materia Civil del Séptimo Circuito contra el fallo en amparo local 6/2006, negado en su contra, emitido el 31 de enero de 2007 por la Sala Constitucional del Tribunal Superior de Justicia de Veracruz.

El cuarto amparo directo, registrado con el expediente número AD309/2007, fue interpuesto el 28 de febrero de 2007 por el ciudadano Octavio Ignacio Escobar Bernal ante el Primer Tribunal Colegiado en Materia Administrativa del Séptimo Circuito contra el fallo en amparo local 5/2006, negado en su contra, emitido el 2 de febrero de 2007 por la Sala Constitucional del Tribunal Superior de Justicia de Veracruz.

En los tres amparos directos recién referidos correspondientes al 2007 (AD-175/2007, AD-190/2007 y AD-309/2007) los quejosos adujeron que el órgano jurisdiccional constitucional local al dictar su sentencia violó en su contra los artículos 14 y 16 de la Constitución federal, es decir, se actualizó una violación "indirecta" a la carta magna. Los quejosos señalaron de manera general que el órgano local no fundamentó y motivó bien sus sentencias en cuanto a que no encuadraron en lo establecido en la legislación local secundaria (artículo 54 de la Ley de Protección de Derechos Humanos del Estado).

Los tribunales federales estimaron que los juicios de amparo sí eran procedentes contra las sentencias en amparo local. Lo cual les permitió entrar al

9 La tesis se publicó en el SJFG9, tomo XV, de abril de 2002, p. 1371, con la denominación VII.1o.P.137 P y número de registro 187,046, cuyo rubro es: Tribunales colegiados de circuito. Carecen de competencia legal para conocer, en amparo directo, de las resoluciones dictadas por la Sala Constitucional del Tribunal Superior del Estado en el recurso de queja interpuesto contra el acuerdo de no ejercicio de la acción penal (legislación del estado de Veracruz). 
fondo del asunto y confirmar las sentencias del tribunal constitucional local en el sentido de negar a los quejosos el amparo y protección de la justicia de la Unión. Los argumentos generales de los tribunales colegiados para negar el amparo fueron en el sentido de que los actores no habían probado sus acciones en cuanto a que no probaron que los conceptos de violación esgrimidos en su contra fueran ciertos. Por tanto, no demostraron que se hubieran violado en su contra los artículos 14 y 16 del texto supremo.

Como se advierte, los criterios esgrimidos por los tres distintos tribunales colegiados al resolver los tres amparos directos anotados, fueron en el mismo sentido en cuanto a aceptar la procedencia del juicio de amparo contra las sentencias en amparo local. Sin embargo, sus posturas las evocaron de una manera muy genérica y confusa. En pocas palabras, dijeron que sí procedía el amparo federal pero no especificaron cómo.

El quinto amparo directo, registrado con el expediente número AD314/2007, fue interpuesto el 28 de febrero de 2007 por el ciudadano Jesús Antonio Marcial Cisneros ante el Segundo Tribunal Colegiado en Materia Administrativa del Séptimo Circuito contra el fallo en amparo local 3/2006, negado en su contra, emitido el 31 de enero de 2007 por la Sala Constitucional del Tribunal Superior de Justicia de Veracruz.

El sexto amparo directo, registrado con el expediente número AD-543/2007, fue interpuesto el 28 de febrero de 2007 por el ciudadano Pascual Chontal Cayetano ante el Segundo Tribunal Colegiado en Materia Administrativa del Séptimo Circuito contra el fallo en amparo local 2/2006, negado en su contra, emitido el 1o. de febrero de 2007 por la Sala Constitucional del Tribunal Superior de Justicia de Veracruz.

El séptimo amparo directo, registrado con el expediente número AD633/2007, fue interpuesto el 23 de febrero de 2007 por el ciudadano León Ignacio Ruiz Ponce ante el Segundo Tribunal Colegiado en Materia Administrativa del Séptimo Circuito contra el fallo en amparo local 7/2006, sobreseído en su contra, emitido el 31 de enero de 2007 por la Sala Constitucional del Tribunal Superior de Justicia de Veracruz.

Cabe señalar también que, previo a que analicemos los amparos directos, se interpuso un octavo amparo federal, pero éste de tipo indirecto, registrado con el número de expediente AI-1282/2008, ante el Juzgado Segundo de Distrito en el Estado de Veracruz. El quejoso, quien es un ciudadano veracruzano, señaló como autoridades responsables a los integrantes de un órgano constitucional autónomo de Veracruz. El acto reclamado adu- 
cido por el quejoso fue la resolución definitiva emitida el 29 de octubre de 2008 por la Sala Constitucional veracruzana, resolución derivada del juicio $1 \mathrm{JP} / 2008$. La sentencia local favoreció a dicho órgano constitucional autónomo en detrimento de los derechos del propio quejoso. La resolución del Juzgado de Distrito se dictó en diciembre de 2008. El sentido de dicha resolución lo desconocemos. ${ }^{10}$

Como se aprecia, los tres amparos directos recién anotados se promovieron ante el mismo Segundo Tribunal Colegiado en Materia Administrativa del Séptimo Circuito. En dichos amparos los quejosos adujeron que el órgano jurisdiccional constitucional local al dictar sus sentencias violó en su contra los artículos 14 y 16 de la Constitución federal, es decir, se actualizó una violación "indirecta" a la Carta Magna. Los quejosos señalaron de manera general que el tribunal local no había fundamentado ni motivado bien sus sentencias en cuanto a que éstas no encuadraron en lo establecido en la legislación local secundaria (en los dos primeros amparos [314/2007 y 543/2007], el artículo 54 de la Ley de Protección de Derechos Humanos del Estado y en el tercer amparo [633/2007], preceptos del Código 590 Electoral para el Estado de Veracruz).

Con fundamento en los artículos 76 al 79 de la Ley de Amparo, así como en los numerales 103 y 107 de la Constitución federal, interpretados contrario sensu, el tribunal federal se declaró legalmente incompetente para conocer de las demandas de amparo y, en consecuencia, desechó las mismas. Los argumentos generales del tribunal de amparo fueron en el sentido de que el actor no había probado su acción en cuanto a que no demostró que los conceptos de violación esgrimidos en su contra fueran ciertos. Por tanto, no comprobó que se hubieran violado en su contra los artículos 14 y 16 del texto supremo.

Sin embargo, los argumentos contundentes para desechar la demanda de amparo y pronunciarse por la no procedencia de este medio de control federal contra las sentencias en amparo local, fueron apoyados en dos tesis (una de jurisprudencia y otra aislada) emitidas por la Suprema Corte que en lo conducente la primera señalaba que la Constitución federal establece 5 órdenes jurídicos, entre ellos el constitucional, el cual establece en su aspecto orgánico el sistema de competencias de dichos órdenes. Y que

10 Desafortunadamente no contamos con suficiente información para analizar los conceptos de violación esgrimidos por el quejoso, así como los argumentos de la resolución federal por parte del juez de Distrito. 
como tribunal constitucional, le corresponde a la Suprema Corte definir la esfera competencial de tales órdenes jurídicos y, en su caso, salvaguardarla. ${ }^{11}$ Mientras que la tesis aislada en lo conducente aduce que a través de la interpretación de algunos preceptos de la Constitución veracruzana, se deduce que la Sala Constitucional de dicho estado tiene competencia sólo para conocer y resolver del amparo local, pero únicamente en cuanto hace a la salvaguarda de los derechos humanos previstos en la propia Constitución local. ${ }^{12}$

Por tanto, según los tribunales colegiados su resolución dictada en el sentido de desechar las respectivas demandas de amparo cual, no configuraba una denegación de justicia, sino que constituía el reconocimiento y respecto de la autonomía judicial de los estados de la Federación.

Cabe señalar que los mencionados amparos directos 314/2007, 633/2007 y 543/2007 dieron pauta para que este mismo Segundo Tribunal Colegiado en Materia Administrativa del Séptimo Circuito emitiera una tesis aislada en el sentido de considerar que no era procedente el juicio de amparo contra las sentencias dictadas en amparo local, ${ }^{13}$ fundamentado en lo general, como ya se anotó, en un criterio esgrimido por la Corte.

Consideramos necesario advertir también que el criterio similar sustentado por el Segundo Tribunal Colegiado en Materia Civil, el Tercer Tribunal Colegiado en Materia Civil y el Primer Tribunal Colegiado en Materia Administrativa, los tres del Séptimo Circuito, para emitir sus respectivas

11 El rubro de la tesis de jurisprudencia, cuyo número es P./J. 136/2005, es el de: Estado mexicano. Órdenes jurídicos que lo integran, la cual fue publicada en el SJFG9, tomo XXII, octubre de 2005, p. 2062, con el número de registro 177006.

12 El rubro de la tesis aislada, cuyo número es P. XXXIII/2002, es el de: Controversia constitucional. La facultad otorgada a la Sala Constitucional del Tribunal Superior de Justicia del Estado de Veracruz-Llave para conocer y resolver el juicio de protección de derechos humanos, previsto en la Constitución Política de esa entidad federativa, no invade la esfera de atribuciones de los tribunales de la Federación, pues aquél se limita a salvaguardar exclusivamente los derechos humanos que establece el propio ordenamiento local, la cual fue publicada en el SJFG9, tomo XVI, agosto de 2002, p. 903, con el número de registro 186307.

13 El rubro de la tesis aislada, cuyo número es VII.2do.A. K, corresponde al de: Sentencias dictadas por la Sala Constitucional del Tribunal Superior de Justicia del Estado de Veracruz. Los tribunales de amparo carecen de competencia para conocer de la impugnación de las resoluciones emitidas por aquélla al resolver el juicio de protección de derechos humanos previsto en la Constitución de dicha entidad federativa, la cual fue publicada en el SJFG9, t. XXVI, noviembre de 2007, p. 762, con el número de registro 170900 . 
sentencias de amparo directo (314/2007, 543/2007 y 633/2007), en el sentido de sostener que el juicio de amparo era procedente contra las sentencias en amparo local y contrario al criterio sustentado (y establecido como tesis) por parte del Segundo Tribunal Colegiado en Materia Administrativa del Séptimo Circuito en el sentido de que el amparo federal no era procedente contra las sentencias en amparo local, generó que la Sala Constitucional del Tribunal Superior de Justicia de Veracruz planteara ante la Suprema Corte una denuncia de contradicción de tesis, registrada con el número 350/2009, misma que fue admitida el 4 de septiembre de 2009. La cual por orden de turno y por la naturaleza administrativa del asunto le correspondió conocerla a la ponencia de la ministra Margarita Beatriz Luna Ramos, misma que en su lista turnó el asunto al Pleno del alto tribunal. Se advierte también que la denuncia de contradicción de tesis por parte de la Sala Constitucional se efectuó para dar cumplimiento al auto de 31 de agosto de 2009 en el expediente del amparo local 7/2007.

\section{Análisis}

En los siete amparos directos (AD-343/2001,AD-175/2007, AD-190/2007, AD-309/2007, AD-314/2007, AD-543/2007 y AD-633/2007) los quejosos reclamaron como violada en su contra la garantía de legalidad, establecida en los artículos 14 y 16 de la Constitución federal (es decir, violaciones "indirectas" a la carta magna). Los argumentos generales que esgrimieron los quejosos fueron que los actos reclamados, es decir, las sentencias en amparo local no estuvieron bien motivadas ni fundamentadas (por ejemplo, en los amparos AD-175/2007, AD-190/2007 y AD-309/2007 la falta de fundamentación consistió en que las sentencias locales respectivas no encuadraron en lo establecido en la legislación local secundaria: artículo 54 de la Ley de Protección de Derechos Humanos del Estado de Veracruz).

Cabe señalar que en uno de éstos amparos (AD-343/2001), además de señalar como violada la garantía de legalidad, el quejoso reclamó que se habían conculcado en su contra su derecho a la justicia (acceso a los tribunales), así como su garantía como inculpado, establecidos en los artículos 17 y 20 constitucionales (es decir, violaciones directas a la norma fundamental).

Respecto a los razonamientos esgrimidos por los magistrados federales de amparo sobre el sentido de sus resoluciones, se tiene que en el amparo AD-343/2001 los argumentos para desechar la demanda se enfocaron en 
que la resolución judicial impugnada fue dictada fuera del juicio de amparo local; por tanto, no constituía una sentencia definitiva sino una resolución que no ponía fin al juicio, la cual debía ser combatida en amparo indirecto.

En los amparos AD-175/2007, AD-190/2007 y AD-309/2007 los tribunales colegiados de circuito, para negar los mismos, argumentaron que los quejosos no habían probado sus acciones en cuanto a que no mostraron evidencia de que los conceptos de violación esgrimidos en su contra fueran ciertos. Sin embargo, los magistrados federales, al considerar entrar al estudio de fondo, señalaron de manera genérica que el amparo directo sí era procedente contra las sentencias en amparo local emitidas por la Sala Constitucional del Tribunal Superior de Justicia de Veracruz; no obstante, no especificaron ni detallaron en qué consistía dicha procedencia.

En los amparos AD-314/2007,AD-543/2007 y 633/2007 los magistrados federales se centraron en sostener que el amparo directo no era procedente contra las sentencias en amparo local dictadas por la Sala Constitucional veracruzana. Para tal efecto, con apoyo en dos tesis de la Suprema Corte, el tribunal colegiado de circuito argumentó que era incompetente para conocer de amparos locales, en razón de que la admisión de una demanda de amparo local (y la substanciación del juicio) constituía un quebranto de la autonomía judicial de los estados de la Federación. Ya que en el caso del estado de Veracruz - seguía argumentando el tribunal federal de amparosu Sala Constitucional es la única competente para conocer y resolver el amparo local establecido en su normativa, pero únicamente contra la violación de los derechos fundamentales estipulados en su Constitución local.

Con este argumento principal el tribunal colegiado de circuito se declaró incompetente para conocer del amparo local, pero además adujo que los quejosos no habían probado su acción en el sentido de que no ofrecieron evidencia de que los derechos fundamentales señalados como violados fueran ciertos. Por tanto, el tribunal federal de amparo desechó las demandas de amparo local.

De los sentidos de las resoluciones en amparo federal, se observa que en la mayoría los tribunales colegiados de circuito no llegaron al estudio de fondo (uno sobreseído y cuatro desechados), y en los amparos que sí llegaron a tal estudio (cuatro), les negaron a sus promoventes la protección de la justicia federal.

En lo correspondiente a los criterios interpretativos generados de los amparos federales, tenemos que del AD-343/2001 se derivó la tesis aislada 
VIII. 1o. P 137 P/2002, emitida por el Primer Tribunal Colegiado en Materia Penal del Séptimo Circuito. La tesis en lo conducente y de acuerdo con su rubro señala que los tribunales colegiados de circuito carecen de competencia para conocer en amparo directo de las resoluciones dictadas por la Sala Constitucional veracruzana en el recurso de queja interpuesto contra el acuerdo de no ejercicio de la acción penal.

En esta tesis aislada el tribunal de amparo se pronunció únicamente sobre los supuestos de procedencia del amparo directo, haciendo una muy breve diferenciación sobre un supuesto de procedencia del amparo indirecto. El criterio de interpretación se centró en dilucidar la naturaleza del acto impugnado, así como la etapa procesal en la que fue emitido.

Precisa que fue un "acuerdo" dictado en las diligencias de la averiguación previa seguidas por el Ministerio Público en la causa penal del fuero común, registrada en el toca 237/2001 de la Sala Penal del Tribunal Superior de Justicia de Veracruz; del cual derivó el amparo local 1JP/2001.

De lo anterior se constata que el acuerdo impugnado, aunque fue dictado por un tribunal judicial, no configuró una sentencia definitiva o una resolución que haya puesto fin a un juicio o que lo haya dado por concluido. Esto nos confirma que el acuerdo fue dictado fuera del juicio de amparo local, lo cual constituye un acto reclamable en amparo indirecto, según lo dispone el artículo 114, fracción III, de la Ley de Amparo.

Respecto a la contradicción de tesis planteada por la Sala Constitucional veracruzana ante la Suprema Corte (en espera de ser resuelta por el Pleno de la propia Corte), se observa que fue generada de las sentencias y resoluciones emitidas en amparo directo por cuatro tribunales colegiados del séptimo circuito. En lo esencial, tres de éstos sostienen que el amparo directo es procedente contra las sentencias en amparo local, mientras que el otro restante, afirma lo contrario.

El argumento fundamental de los tribunales colegiados que sostienen la improcedencia del amparo federal contra el local, es que los órganos constitucionales locales que emiten dicho amparo local pertenecen al orden jurídico denominado "constitucional" y que, por tanto, la Suprema Corte de Justicia como máximo órgano jurisdiccional o, más bien, como tribunal constitucional que es, debe definir la esfera competencial de dichos órganos constitucionales locales. También sostienen que los órganos constitucionales locales (en este caso el de Veracruz) tienen perfectamente delimitada su competencia para emitir amparos locales contra la violación de los derechos 
fundamentales establecidos únicamente en su Constitución local, lo cual "no invade la esfera de atribuciones de los tribunales federales".

Esto último que hemos entrecomillado nos parece que adolece de vaguedad, en el sentido de que no precisan si se refieren a que la resolución que en amparo local emite el órgano constitucional estatal es definitiva e inatacable y, por tanto, no puede combatirse ante los tribunales federales. Sin embargo, habría que reflexionar si en un sistema federal como el nuestro, con una Constitución general, los tribunales federales pueden ejercer el control constitucional (en virtud del principio de supremacía constitucional - federal-) sobre la jurisdicción local cuando se reclame la violación de un precepto de la propia Constitución general.

En este sentido, como ya lo anotamos arriba, si se nos permite hablar de un "federalismo judicial constitucional" (en el cual convergen dos órdenes constitucionales distintos: uno federal y uno local) y lo relacionamos con el tema de la revisión (que estudiamos arriba), que técnicamente configura una "apelación" (la cual tiene como función principal la "corrección de errores" de un órgano jurisdiccional jerárquicamente inferior por parte de uno superior), tenemos que existe al menos una vía para "invadir" la esfera competencial de los tribunales federales de amparo, que es cuando el quejoso considera que el juez constitucional estatal, al resolver el amparo local promovido por aquél, violó en su contra la garantía de legalidad, lo cual constituye una violación "indirecta" a la Constitución federal. En este caso procede la revisión ante un órgano jurisdiccional federal para confirmar si efectivamente el juez de amparo local violó o no dicha garantía de legalidad, la cual configura una garantía fundamental.

Por otro lado, en cuanto a los tribunales federales de amparo que consideraron que sí procedía el amparo federal contra el amparo local, se tiene que sus argumentos para sostener dicha afirmación fueron muy generales y confusos. En pocas palabras, dijeron que sí procedía pero no dijeron cómo.

Finalmente, respecto a la duración de los juicios de amparo, tanto locales como federales, se observa que los 18 amparos locales cuantificados en promedio duraron 6 meses $1 / 2$ (197 días naturales) para resolverse, mientras que los 8 amparos federales ( 7 amparos directos y 1 indirecto) en promedio se demoraron en resolverse 3 meses (84 días naturales). También podemos observar que los 7 juicios de amparo local y federal cuantificados conjuntamente, en promedio tardaron en resolverse 7 meses (206 días naturales), 7 meses que esperaron los quejosos (desde la fecha de presentación de la 
demanda de amparo local hasta la fecha de la resolución en amparo federal) para conocer si sus derechos fundamentales que reclamaron como violados, habían sido realmente protegidos.

\section{CONCLUSIONES Y PROPUESTAS}

La labor empírica realizada en esta exposición, respondió a las interrogantes planteadas al inicio de este trabajo y, además, permitió comparar la veracidad de diversas opiniones que sobre el federalismo judicial constitucional en materia de amparo se han vertido actualmente. Estas afirmaciones y las que siguen están sólidamente apoyadas en nuestras tablas estadísticas.

No obstante de que actualmente es prematuro elaborar un "diagnóstico" y determinar "tendencias" sobre la reciente y escasamente impartida justicia constitucional local en materia de amparo o, mejor dicho, en materia de protección de derechos fundamentales (25 amparos locales) ${ }^{14}$ así como el mucho menos utilizado control constitucional federal de amparo sobre el amparo local (8 amparos federales), creemos que ya existen algunos elementos básicos que nos permiten emitir aunque sea de manera esquemática y parcial algunas reflexiones sobre la relación "amparo federal vs. amparo local" (que configuran el federalismo judicial constitucional en materia de amparo).

La tendencia cuantificada en el uso del amparo local se inclina por la no protección de las garantías fundamentales locales, lo cual permite que el ciudadano opte por la búsqueda de la protección de la justicia federal a través del juicio de amparo, argumentando en lo conducente una violación indirecta a la Constitución general, es decir, una violación a las garantías constitucionales adjetivas o de legalidad o, de plano, una violación directa a las garantías sustantivas de la propia Constitución federal.

Esto señala que los quejosos prefieren el amparo federal. Sin embargo, éste tampoco ha llenado sus expectativas en el sentido de que, por lo me-

${ }^{14}$ Como lo señalamos a lo largo de este trabajo, tenemos información de que en el periodo 2002-2009 en Tlaxcala se radicaron 91 demandas de amparo local. De éstos 91 posibles juicios de amparo local, como también ya lo anotamos, únicamente 5 sentencias en amparo local se han hecho públicas, mismas que ya analizamos aquí. También es necesario señalar que si no nos fue posible obtener las 86 posibles sentencias de amparo local tlaxcaltecas, menos nos fue posible conocer siquiera si alguna de éstas posibles resoluciones locales fueron impugnadas en amparo federal. 
nos en materia de derechos humanos locales, no los ha reivindicado de la violación de los mismos.

En cuanto a la efectividad (eficiencia y eficacia) del federalismo judicial constitucional en materia de amparo (entendiendo a la eficiencia como la prontitud de los jueces constitucionales - federales y locales - de amparo para resolver sus asuntos, y a la eficacia, como el logro de los fines generales de la propia justicia constitucional de amparo en el sentido de, a través de sus sentencias, restituir a los ciudadanos sus derechos violados), se tiene que, de acuerdo con los datos estadísticos y valorativos ofrecidos en esta exposición, la eficiencia de la justicia constitucional local de amparo es aceptable, en el sentido de que sus sentencias se emiten en un tiempo razonable (6 meses y medio); que la calidad de las sentencias de los jueces constitucionales locales son eficaces, en razón de que aunque son revisadas esporádicamente por la jurisdicción federal de amparo, no son modificadas en lo absoluto. Lo cual configura el carácter definitivo y firme de dichas sentencias locales. Situación que fortalece la autonomía judicial de las entidades federativas y, en consecuencia, consolida su "independencia" con respecto a la propia jurisdicción constitucional federal.

En cuanto a la escasamente ejercida justicia constitucional federal de amparo contra los amparos locales, se observa una efectividad relativa en el sentido de que su eficacia se ha visto limitada al no poder conceder a los quejosos la protección constitucional del amparo federal (de los siete amparos promovidos tres se negaron y cuatro se desecharon),${ }^{15}$ mientras que la eficiencia se mostró buena al resolver los amparos en apenas 3 meses.

Como lo señalamos arriba, aunque aún no se observa una eficacia real del amparo local en cuanto a la tutela de los derechos fundamentales de carácter local, creemos que tal afirmación será viable en la medida en que este medio de control vaya alcanzando los objetivos que por naturaleza

15 Como lo anotamos con antelación, los argumentos del tribunal colegiado de circuito que sostuvo la procedencia del amparo directo contra los amparos locales, fueron confusos. Lo cual nos lleva a pensar que aunque admitió 3 demandas de amparo local y decidió negar a los quejosos la protección constitucional federal, no tuvo los elementos necesarios para otorgarles dicha protección. Esperamos que esta confusión del tribunal colegiado que está en favor de la procedencia del amparo federal contra el amparo local y la postura de los colegiados que niegan ésta posibilidad, sea aclarada por el Pleno de la Suprema Corte, el cual a partir del 10 de febrero del 2010 tiene en sus manos la responsabilidad de resolver la contradicción de tesis que, para efectos de dilucidar dicho dilema, le fue planteada. 
tiene. Al lograr dichos fines, consideramos que el amparo local tendrá un efecto histórico contrario a lo ocurrido con la casación mexicana de finales del siglo XIX con respecto del amparo federal, ${ }^{16}$ el cual desplazó a la propia casación debido a que, no obstante la similitud de funciones con nuestro juicio constitucional, ésta institución de origen francés era de difícil acceso a los ciudadanos por su carácter tan formalista.

En este sentido, aunque de modo contrario, creemos que en muchos aspectos, principalmente en cuestiones de defensa de derechos fundamentales locales, el amparo local desplazará paulatinamente al amparo federal (por lo menos en la práctica jurisdiccional de los estados), debido al carácter tan formalista que el propio amparo federal ha arropado con el tiempo (de igual manera como le ocurrió a la casación).

Para lograr dicho objetivo, consideramos que se requiere fortalecer al propio amparo local en el sentido de darlo a conocer mayormente a la sociedad, así como perfeccionarlo tanto técnica como instrumentalmente con el fin de hacerlo más accesible a los justiciables en sus respectivas entidades federativas $y$, consecuentemente, concretar su finalidad para la que fue creado, que es la protección real de los derechos fundamentales.

Por otro lado, como lo señalamos al inicio de este trabajo, una de las posibles cuestiones que ha generado el establecimiento de la jurisdicción constitucional local de amparo, ha sido la falta de coordinación normativa e institucional con la jurisdicción federal de amparo. A continuación nos referiremos especialmente al papel que la Suprema Corte tiene en torno a dicha cuestión, en razón de que configura el máximo órgano de control de constitucionalidad en el país y, por ende, un actor fundamental en esta dinámica. La referencia la haremos en tono de diagnóstico-propuesta.

El rol del tribunal constitucional nacional es esencial porque sus decisiones pueden conducir a la apertura o a la obstaculización de un espacio institucional propio para los sistemas de justicia constitucional estatal. Sobre el particular han existido avances significativos a pesar de que en ocasiones ha existido cierta reticencia a la idea de que en México los tribunales estatales puedan tutelar derechos fundamentales de fuente estatal (o, incluso,

16 Para una exposición sobre la casación histórica y su desplazamiento por el amparo federal, véase nuestro artículo "Surgimiento y decadencia de la casación en México", Reforma Judicial. Revista Mexicana de Justicia, núm. 3, enero-junio, 2004. 
de fuente internacional). ${ }^{17}$ No obstante ello, los esfuerzos para que exista un posicionamiento cada vez más contundente de nuestro más alto tribunal deben continuar para tener definiciones precisas en diversos aspectos.

Un aspecto fundamental es el tema de los catálogos de derechos en las entidades federativas. La existencia de los mismos es acorde con la autonomía que la Constitución mexicana reserva a las mismas, e inexorable para considerar a las constituciones estatales como verdaderas constituciones. Los catálogos de derechos de las entidades federativas pueden reproducir algunos o todos los derechos que contiene la Constitución general, ampliarlos o incorporarlos con otro tipo de lenguaje normativo, de forma más o menos explícita, sin que eso signifique que dejen de considerarse derechos de carácter estatal. Ya que en su calidad de derechos de fuente estatal, existe la obligación de la entidad federativa respectiva de protegerlos mediante instrumentos de naturaleza procesal, también de carácter estatal.

En lo que corresponde al control constitucional federal por medio del amparo, es necesario señalar que las resoluciones de los tribunales estatales en control de constitucionalidad, por ser resoluciones jurisdiccionales "atípicas", creemos, no pueden ser impugnadas en amparo directo ante los tribunales colegiados de circuito, y que en ese sentido, debe considerarse que los tribunales constitucionales locales no atienden cuestiones de legalidad sino de auténtica "constitucionalidad estatal". ${ }^{18}$

Sobre el tema de la interpretación y jurisprudencia, existe la posibilidad de que los tribunales estatales interpreten la Constitución general y apliquen la jurisprudencia emanada por los tribunales de la Federación en aquellos asuntos en donde exista identidad de derechos, de competencia o de facultades, sin que eso signifique que la interpretación deba ser necesariamente igual.

Ante la eventual vulneración del principio de legalidad, como a menudo sucede, en un contexto en el que muchas de las constituciones incorporan este principio como derecho fundamental, un asunto local en el que el acto impugnado proviene de una autoridad de carácter estatal y el derecho vulnerado tiene cobertura estatal, podría sustanciarse en doble instancia, local y federal, y terminaría siendo resuelto por los tribunales federales, cuando

17 Sobre la incorporación de los derechos en las entidades federativas, véase el detallado estudio de Jorge Ulises Carmona Tinoco, "La situación actual de la incorporación de los derechos humanos en las constituciones locales mexicanas" (inédito).

18 Respecto al tema véase el acucioso trabajo de César Iván Astudillo Reyes, "La justicia constitucional en las entidades federativas. Apuntes para valorar su desempeño" (inédito). 
en realidad debería ser decidido por los tribunales locales aplicando la jurisprudencia que sobre el particular haya emitido la Corte.

En el mismo tenor, los tribunales estatales deben, en principio, vincularse a las pautas interpretativas de la Corte, y otorgar una protección equivalente en tratándose de identidad de "contenido normativo", pero que están posibilitados para ampliar el radio de protección en función de la interpretación que puedan realizar de su texto, en función de su propio contexto. Esto lleva a destacar que la protección otorgada por la Corte debe considerarse como el "mínimo" de protección y que la conferida por los tribunales locales debe entenderse como el "máximo".

Lo anterior significa la necesidad de replantear las relaciones entre los tribunales de la Federación y los locales. Se trata de que cada uno tenga un espacio propio en donde unos no se sobrepongan a los otros, y en donde se sientan las bases para que puedan existir verdaderas relaciones de coordinación y complementariedad.

De acuerdo con lo expuesto, se puede concluir que el futuro de la justicia constitucional de las entidades federativas depende de varios factores generales, entre los cuales destacan el de que la propia jurisdicción contenciosa constitucional local sea fortalecida por sí misma a través de sus instrumentos normativos e institucionales. Asimismo, es necesario evitar toda injerencia política ajena a la función jurisdiccional de la propia justicia local. Respecto a la contribución requerida por parte de la jurisdicción federal para el logro del futuro promisorio de la justicia local, ya quedó señalado arriba.

Con la coordinación normativa e institucional adecuada entre la jurisdicción constitucional federal de amparo y la de carácter local de amparo se evitará en lo posible que la justicia federal parezca que "obstaculiza" el desarrollo de la justicia local, y que la propia jurisdicción local de amparo, ante la relativa reproducción normativa e institucional que ha realizado del sistema de control constitucional federal de amparo, parezca que "compite" con la jurisdicción de índole federal. Lo cual desvirtúa el carácter sistémico de la propia justicia constitucional en el sentido de complementariedad entre una jurisdicción y otra en cuanto a la tutela integral de los derechos y garantías constitucionales.

Por consiguiente, el futuro de la justicia constitucional local en materia de amparo parece estar encaminado a configurar un sistema de control constitucional sólido e independiente (en el sentido de autonomía institucional y técnico procesal), aunque complementario de la justicia federal (en el 
sentido de la tutela plena de los derechos fundamentales). Si se concreta lo anterior, ciertamente coadyuvará a "descargar" a la propia jurisdicción constitucional federal del considerable número de facultades y asuntos radicados en la misma y, finalmente, ayudará a consolidar un verdadero federalismo judicial constitucional.

\section{FUENTES DE INFORMACIÓN}

Astudillo Reyes, César Iván, "La justicia constitucional en las entidades federativas. Apuntes para valorar su desempeño" (inédito).

BARClAY, Scott, "Posner's Economic Model and the Decision to Appeal", Justice System Journal, vol. 19, núm. 1.

BATOR, Paul et al., Hart and Wechsler's the Federal Courts and the Federal System, 3a. ed., Nueva York, The Foundation Press, Inc., 1988.

Bustillos, Julio, "Surgimiento y decadencia de la casación en México", Reforma Judicial. Revista Mexicana de Justicia, núm. 3, enero-junio de 2004.

, El amparo directo en México. Evolución y realidad actual, México, Porrúa-UNAM, Instituto de Investigaciones Jurídicas, 2008.

, La justicia constitucional en México. Análisis cuantitativo de las resoluciones judiciales en materia constitucional, México, UNAM, Instituto de Investigaciones Jurídicas, 2009.

, Federalismo judicial. Breve estudio sobre la relación entre la justicia local y la justicia federal a través de las resoluciones locales impugnadas en amparo federal, México, UNAM, Instituto de Investigaciones Jurídicas, 2010.

CARMONA TinOCO, Jorge Ulises, "La situación actual de la incorporación de los derechos humanos en las constituciones locales mexicanas". (Inédito)

ComBA, Mario, Esperienze federaliste tra garantismo e democrazia. Il "judicial federalism” negli Stati Uniti, Napoli, Casa Editrice Jovene, 1996.

FiX-ZAMUDiO, Héctor, "El Poder Judicial y el federalismo mexicano”, Revista Ameinape, Querétaro, núm. 1, enero-junio de 1996.

GudiÑo Pelayo, José de Jesús, "Federalismo e independencia judicial", Jus Semper Loquitur, núm. 30, octubre-diciembre de 2000.

HeRnÁndeZ MartíneZ, María del Pilar, "Del federalismo judicial”, Re- 
forma Judicial. Revista Mexicana de Justicia, núm. 2, julio-diciembre de 2003.

RuIZ, Gregorio, Federalismo judicial (el modelo americano), Madrid, Civitas, 1994.

SHAPIRO, Martin, “Appeal”, Law and Society Review, vol. 14, núm. 3, primavera de 1980.

SHAVELL, Steven "The Appeals Process as a Means of Error Correction", Journal of Legal Studies, vol. 24, núm. 2, junio de 1995.

Fecha de recepción: 12 de marzo de 2011.

Fecha de dictamen: 5 de febrero de 2012.

DR (c) 2012, Universidad Nacional Autónoma de México, Instituto de Investigaciones Jurídicas 